Cecilie Flo Jahreie

Post doc., InterMedia

University of Oslo

VISIONS

Conference

2011:

Teacher

Education

\title{
Learning to teach at the boundaries between university courses and internships
}

\begin{abstract}
The theory-practice gap is a recurring problem in teacher education. This article is concerned with how student teachers learn to teach at the boundaries between university courses and internships. I investigate how participants create meaning around scientific concepts, and how they respond to the institutional context they act in, thereby making it relevant. These questions are addressed by employing the Cultural-Historical Activity Theory. The study took place at the Department of Teacher Education and School Research at the University of Oslo. The data are based on extensive observations in various settings at the university and schools offering internships. Interaction analysis is used to analyze participation in different settings. The analysis shows that the students encounter divergent structures and discourses in the course of their learning trajectories. What counts as knowledge differs between universities and schools, and within the university. In teacher-led situations, student teachers are positioned in relation to the teachers and mentors, with few opportunities for knowledge construction. The study also shows instances where the student teachers explore and elaborate upon knowledge in new ways, such as in group collaborations. From the perspective of the student, it seems reasonable to argue that the contradictions within and between the activity systems serve as constraints on learning. To create coherent programs, concepts and ideas about teaching and learning have to be shared by Departments of Teacher Education and partner schools.
\end{abstract}

\section{Introduction}

Fragmentation between university courses and internships, or the theory-practice gap, as it is often called, has been a recurring problem in teacher education. In recent years, the need to create coherence between university coursework and internship experiences in learning to teach has received increased attention (Darling-Hammond \& Bransford, 2005; Furlong, McNamara, Campbell, Howson, \& Lewis, 2008; Grossman, Hammerness, McDonald, \& Ronfeldt, 2008). In Norway, the White Paper on teacher education presents a number of efforts aimed at increasing the quality of teachers and teacher education and a 
structured framework for collaboration between Departments of Teacher Education (DTEs) and schools is emphasized (Ministry of Education and Research, 2009). Even though there has been a strong policy focus both in Norway and internationally to construct coherent programs, there are few studies focusing on how the boundaries between DTEs and schools are transcended. In a recent study of perceptions of coherence, coherence was defined both according to concepts-ideas or visions, but also according to structures-logistics or design of learning opportunities (Grossman, et al., 2008). Their findings show that several structural features are significant in establishing coherent programs. Rather than focusing on structural features, however, the focus this study is concept coherence within and between DTEs and schools. More specifically, my concern is how concepts are interpreted among participants.

The majority of research on student learning only focuses on one site for learning, and most of this research is viewed from the perspective of internships. Internships are often devised without clear goals and lack connections to university coursework (Guyton \& McIntyre, 1990). Studies of talks between mentors and students led to the robust findings that the talks are first and foremost about methods that work and curriculum delivery, where students are presented with the way teachers think and act on an everyday basis (Edwards \& Protheroe, 2003; Ottesen, 2006; Sundli, 2001). Teachers have problems articulating practical knowledge and relating their practice to theories of how pupils learn, and they lack knowledge of specific teaching strategies (Burn, 2007; Edwards \& Protheroe, 2004; Fosse, 2010; Furlong \& Maynard, 1995; Jahreie \& Ottesen, 2010a, 2010b; Ottesen, 2007).

Research on how students learn to teach within the DTEs is limited. Studies show that effective programs give students theoretically grounded tools to use in the classrooms (Darling-Hammond, 2006). A review of Norwegian studies on learning activities in seminars in pedagogy reveal conflicting results. A couple of studies found that the seminars are organized as traditional instructional teaching events with a focus on theory and on how to use and understand a system of concepts. The instruction is characterized as teacher-regulated knowledge transmissions and as lectures (Bråten, Strømsø, \& Olaussen, 2003; Eriksen, 2004). Studies of talks between university teachers and students show that scientific concepts are often highlighted in relation to practical experiences, but the relevance between theory and the task at hand is rarely made explicit for the students (Fosse, 2010; Jahreie \& Ottesen, 2010a). The findings also suggest that students have increased opportunities for participation through these kinds of learning activities (Jahreie \& Ludvigsen, 2003). A common finding across studies is that when students collaborate in small groups, teachers take a distant role, leaving the students to struggle with problem-solving activities more or less on their own (Bråten, et al., 2003; Fosse, 2010). However, more research is needed to obtain more robust findings on students' experiences in DTEs. 
The scarce amount of research that focuses on transcending the boundaries between DTEs and schools is often grounded in Cultural Historical Activity Theory (CHAT), using an interventionist approach to promote learning and change in activity systems. Lambert (2003) designed a learning studio for communication between student teachers, teachers, and practitioners. She found that a task student teachers had worked with during their internships became a boundary object for questioning and analyzing the school institutions. Similarly, Ellis (2008) created a space for communication to highlight the problem of practice between mentors, university teachers, and students and, in this way, promote learning. The study showed that through the intervention, the mentors gradually revealed an alternative conception of teacher agency, which was found to be an important factor in students' learning.

Like Lampert and Ellis, my studies of learning to teach are theoretically grounded in CHAT. Our studies also share a focus on concept coherence between activity systems. However, we conduct our studies in different ways. While they arrange for thoroughly developed interventions, in which the researcher plays an active role as a facilitator who introduces and organizes new tools to improve the setting and achieve coherence, my concern is students' changing participation during teacher education courses held in naturalistic settings. Over the last few years, Ottesen and I have undertaken a series of studies on different aspects of how students learn to teach. We found that students receive conflicting accounts within DTEs (Jahreie \& Ottesen, 2010b) and between DTEs and schools (Jahreie \& Ottesen, 2010a). In a study following students' group work over a period of time, it was found that when students are given time to collaborate, they gain new insights on how to understand the phenomena they are tackling (Jahreie, 2010b). These studies looked at patterns of participation in more detail. This article aims to depict the coherence between DTE and schools by investigating students' participation trajectories during a teacher education course. By focusing on the construction of meaning in different places of learning, my interest is in patterns of interaction, as well as atypical instances of talk, as it is these instances that offer the potential for development.

In the empirical analysis, I investigate how meaning is created in talks between participants, and how the participants, through their actions, respond to the institutional context they are acting, thereby making it relevant. Based on this background, the following two research questions can be deduced:

- How are scientific concepts interpreted among participants across different sites of learning?

- What characterizes participation during the teacher education course? 


\section{Theoretical framework}

From the end of the 1990s and during the 2000s, the sociocultural and CHAT perspective developed into a way of understanding the process of learning to teach (Jahreie, 2010a). The basic idea is that human mental processes have to be understood in relation to the cultural, historical, and institutional settings the individual is participating in at the moment (Wertsch, 1991). Cognitive activities such as thinking are inseparable from the actions that people engage in. This implies that the focus would be on what the students do in a situated practice and how cultural resources are negotiated, used, and transformed in interactions.

Grounding the study in a CHAT approach, I see learning to teach as an activity that is depicted as a group of activity systems, including the activity system of the DTE and the activity system of the school. The two activity systems have different historical objects. While the object of the DTE is students learning and research production, the object of schools is pupils' learning. However, as teacher educators, DTEs and schools collaborate to educate teachers. Thus, there is a potential space at the border between the two activity systems where the participants share student learning as a joint object. Furthermore, in this space, tools, rules, and the division of labor may be shared and moved between activity systems. Whether this actually happens is an empirical question.

Students' learning trajectories are organized across a number of places for learning in the form of mentoring, seminars, lectures, group work and oral exams. In each of these places, or "learning spheres," that constitute a teacher education course, there are different participants with multiple backgrounds, interests, and motives influencing their actions (Jahreie, 2010a). This means that the students face a variety of tasks and expectations across spheres. What counts as knowledge is inherent in the different spheres and is the basis of interaction in the given situation (Ludvigsen, 2009).

Every activity consists of a structure of activities, actions, and operations. The notion of an "object" refers to two different, but interrelated, aspects of the concept, which elucidate the relation between activity and action: the historical, generalized object of the activity system (e.g., students' learning) and the problem or task that the participants are working on at the moment, which are discursively constructed (Engeström, Puonti, \& Seppänen, 2003; Jahreie, 2010a). Participants conceptualize and enact tools and scientific concepts in diverse ways, resulting in differing understandings of how students learn to teach within the same activity system.

When object construction is investigated over time and across activities, boundary is a key concept. Boundaries are part of activities and have historical layers, but become transparent in and through participants' talk and actions (Kerosuo, 2006). The learning trajectories of student teachers are trajectories at and across the boundaries between the DTE and the school. To pass their final 
exams and become certified teachers, student teachers need to attain theoretical knowledge (about their subjects, pedagogy, and methods) and field experience as teachers. Boundaries appear as a terrain of both limits and possibilities for student teachers' learning trajectories.

\section{The study and methods}

This study took place at the Department for Teacher Education and School Research at the University of Oslo. The department was enrolled in a national reform project, the Program for Teacher Education, Technology, and Change (2000-2003), which aimed to create coherence between the university courses and internship experiences. Seminar groups in pedagogy intended to give the students theoretically grounded tools to use in classrooms. Most of the work was collaborative, conducted either with the whole group, around twenty students, or in core groups (in Norwegian: "basisgruppe") of four to six students. The core group worked together in all of their campus and internship activities. The students had two periods of internship. A mentor was assigned to the group for each of the subjects. She/he observed their lessons and had conversations with the group twice a week. The assessment reports from the mentors formed the basis for the evaluation of the students' practice teaching. Portfolio assessment and case assignments were central tools in the new program. The portfolio consisted of a selection of the student's cases and tasks across the different subjects. The students took an interdisciplinary oral exam at the end of the year based on their portfolio.

The data analyzed for this article are produced as part of my thesis. The thesis is built on extensive observations of one core group's participation in all formal learning spheres, both on campus and at the internship, during the oneyear course (2002/2003). The extracts are taken from three of the four articles that are part of the thesis and utilized as illustrations to elucidate how student teachers learn to teach at the boundaries in teacher education. The extracts were chosen either because they show typical patterns of interaction, or interaction that is atypical ${ }^{1}$. The methodological approach is interaction analysis (Jordan \& Henderson, 1995) because it provides an opportunity to study a particular moment, how actions unfold, and how resources are used to conduct certain actions. The ethnographic information provides a background for the analysis of the interactions, which in turn informed ethnographic understanding. The extracts were transcribed from Norwegian to English.

In qualitative method, it is problematic to speak of generalization as being transferred from a study to other settings. Theoretical or analytic generalization is seen as far more important in qualitative research and education research (Eisenhart, 2009). This implies that the generic claims in this article are based 
on a combination of the theoretical approach, the analysis-generated findings, and findings of related studies.

I am interested in investigating how the participants make their ideas, understandings, agreements, and disagreements available to each other and how they make meaning of concepts in different learning spheres. Information that is considered legitimate in the learning sphere is understood as scripts or resources that participants use to interpret the talk and actions of others and to guide their own participation. Scripts can be seen as orientations the participants come to expect after repeated interactions in learning spheres (Engeström, 2008). In the interaction, participants choose to give accounts for the historical script, or for alternative scripts. The division of labor of activity systems may constrain or afford possibilities for agency and action. However, neither entitlement nor legitimacy is a "given" rather they are negotiated in interaction as possibilities for action. Positioning is collectively accomplished through a discursive process wherein one positions oneself and the other participants (Daniels, 2007; Holland, Lachicotte, Skinner, \& Cain, 1998).

\section{Empirical analysis: Making sense of concepts across boundaries}

While the majority of research on student learning only focuses on one site for learning, this study aims to illuminate participation trajectories across the boundaries of different sites. The extracts serve as illustrations of how scientific concepts are interpreted in different learning spheres.

\begin{tabular}{|l|l|l|l|l|}
\hline & Extract 1 & Extract 2 & Extract 3 & Extract 4 and 5 \\
\hline Learning sphere & $\begin{array}{l}\text { Group work at } \\
\text { campus }\end{array}$ & $\begin{array}{l}\text { Mentoring } \\
\text { conversation }\end{array}$ & Seminar pedagogy & Oral examination \\
\hline Time in trajectory & $\begin{array}{l}\text { 2 quarter, after 1 } \\
\text { internship }\end{array}$ & $\begin{array}{l}\text { End of second } \\
\text { internship }\end{array}$ & Fourth quarter & $\begin{array}{l}\text { End of fourth } \\
\text { quarter }\end{array}$ \\
\hline Interaction pattern & Typical & Typical & Atypical & Typical \\
\hline
\end{tabular}

Table 1: Learning trajectory: Overview of extracts

\section{Group work: Negotiating scientific concepts}

The following extract is from students' interaction when working with one of their case assignments on pedagogy. For these assignments, the students are supposed to offer theoretical reflections on practical experiences. Some of the cases are written in collaboration, while others are individual. On the individual cases, students obtain feedback from the other students in their core group. In this extract, Britt and Eli provide feedback on Sara's case, and it is taken from a trajectory where the students were working with two cases over a period of three 
weeks. In this case, the concern is how peer collaboration can promote learning, especially for pupils with special needs. Fifteen minutes before this interaction takes place, the students mention Vygotsky's theory for the first time. In the extract below, the students try to negotiate a mix-up between Vygotsky's ZPD and the P-triangle ${ }^{2}$.

\section{Extract 1}

1. Britt: Yes, I agree. And you've included theory, but you could add a bit more theory to the practical part about what should be done. And you should add that Vygotsky stuff. Because that's sort of (...)

2. Elin: Can you include that triangle, that P-triangle?

3. Sara: Triangle? Practice triangle? [sounds skeptical]

4. Elin: That one [draws a triangle on a paper]. Isn't that something with the pupils here [shows the triangle she has drawn]. And then you can sort of organize the teaching (...) Or no, did I mix them up now (...) You organize the teaching so they have to stretch a bit further to make it.

5. Sara: Hmmm. [sounds skeptical]

6. Elin: You can make the teaching a bit more difficult than you think they can manage.

7. Sara: Oh, yes, like that [sounds skeptical]

8. Elin: Is that the triangle?

9. Britt: (..) No, I thought that was the one (...)

10. Sara: That's the zone of proximal development, isn't it? [Elin tries to say something, approves of what Sara says]

11. Britt Yes, the zone of development.

12. Elin: Oh, yes, that one, yes! But what's the triangle then?

13. Sara: That is (...)

14. Britt: The triangle, that is (...) P1 is (...)

15. Elin: That's us!

16. Britt: Yes, that's us.

17. Elin: Okay.

18. Britt: $\mathrm{P} 1$ is the practical, what happens in the classroom (...)

19. Elin: But if you take the zone of proximal development, is that Vygotsky?

20. Sara: Yes.

There are two aspects of this extract that I want to highlight. The first is how important it is for the students' learning to construct and reconstruct the tools being utilized. The purpose of this conversation is for Britt and Elin to offer feedback and comments on Sara's text. Britt suggests that Sara should use more theory, preferably Vygotsky [1]. Elin follows up by suggesting "the P-triangle" [2]. Sara's response [3] indicates that she is uncertain about the connection Elin makes between Vygotsky and the P-triangle. Elin explains what she means [4] by talking about ZPD, and drawing the "P-triangle."3 However, she interrupts herself by asking whether she has mixed up the two concepts. This is the start of a sequence [4-12] wherein the students address the problem (that they mixed up two scientific concepts). It is a turning point in the conversation when Sara 
interrupts Britt by interjecting, "That's the zone of proximal development, isn't it?” [10]. In this second part of the interaction [13-20], they negotiate a joint understanding of the problem: how to understand the two scientific concepts. This shows that the students both explore and use scientific concepts (tools) to explain the observed phenomena. When discussion about the task prompts the group to question their conflicting understandings of the tools (the concepts of ZPD and P-triangle), they use their reflections about the pupil as a tool to critically reflect on the meaning of the scientific concepts. When they have reached a shared understanding of the two scientific concepts (the problem), they are used as resources or tools to make claims about the pupil.

The second point is how the students use each other as resources in their reflection about scientific concepts. None of the students act as experts; rather, they give each other agency to address problems. In her responses [3, 7], Sara is uncertain about the distinction about the two concepts, and opens negotiation about the meaning of the tools. Elin is then given the agency to define and address the problem $[4,6,8]$. Negotiating the meaning of the tools enables them to collaboratively construct knowledge beyond the capacity of the individual. The collective orientation is seen in how the students construct the task by recognizing that another person may be a resource. The students hold themselves accountable to the other students by consulting each other in the problemsolving process $[2,8,10-12,19]$. Another important aspect of this extract is that the students recognize that it is hard cognitive work to elicit, recognize, and negotiate the use of tools in order to analyze and write the cases.

\section{Mentoring: How to perceive "goals" in education}

A central part of teachers' work is to plan lessons. In the conversation below, the mentor and two of the students, Kris and Geir, discuss a lesson plan written by Kris that will be supervised by the school's principal. An outline of the plan is developed at the DTE and has a didactic profile. Students are expected to create such documents to plan their lessons during their internships. Kris' lesson plan follows the template of a plan they were asked to follow at the seminar on pedagogy just before the internship. In his plan, he uses the definition of goals from one of their textbooks.

\section{Extract 2}

1. Mentor: It is a bit difficult to make a distinction between goals relating to skills, those relating to pedagogical content, and those relating to attitudes. Because everything is interrelated, in a way it gets...

2. Kris: I divide them here to the extent that I find it useful. It can be OK for structuring my thoughts, but I don't bother to press reality into a prescribed form.

3. Mentor: But the goals of the subject, where do you intend to put them? You have goals for the work [the project work] and the competence goals, but you may also need to show that you see a connection between the goals for 

the subject and the goals for the lesson.
4. Kris:
5. Mentor:
6. Kris:
7. Mentor:
Yes. I think that is part of the goals for the work. That's where I will refer to the National Curriculum
But you should write them into your document. You mean that it needs its own heading?
Yes, because Ann [the principal and the school supervisor] is not familiar with this subject, and that is what you are going to make clear here, that you see...the goals are what direct our working day at school. And to know how to break down goals is an essential part of being a teacher. But what you do is to look in the back here [of the textbook]. We have been looking at the goals on the welfare state and then you can just find the goals that fit so you show a connection. But make sure you reduce it; you are not going to put in every goal, but it has to be a connection between the goals that you put in and how you break it down in the lessons.

This sequence illustrates three interesting features and dilemmas of how student teachers learn to teach in the context of an internship. First, it illustrates mentors' assigned position between didactic and practical interests as both, respectively, a teacher educator and a teacher. In the first part of the sequence, the mentor justifies the what and how questions of didactics, thus giving the expected accounts as a teacher educator [1,3]. She underlines that the plan should make explicit a connection between "goals for the subject" and "goals for the lesson." In other words, the student has to take into account how the general goals for social science relate to the learning targets for the subject. It is reasonable to interpret this as a request, even though it is posed as a question. As a teacher, however, the mentor accounts for how to use the national curriculum (NC) in a lesson plan and how teachers are expected to deal with the goals [5, 7]. Breaking down the goals of the NC into targets for their teaching is a significant part of the work of a teacher. The mentor gives three solution strategies. One is local and has to do with the principal's role as supervisor: She does not know the subject, and in order for her to understand the lesson plan, Kris needs to clarify the goals. The second is cultural: Teaching is regulated in society through the NC. Thus, it is vital to be explicit about the connection between the specific goals and the goals for the lesson. In his work as a teacher, Kris is also accountable to the mandate of teachers as expressed in the NC concerning the legal responsibilities of teachers. In the last part of the mentor's utterance [7], however, she suggests using the learning targets developed for the lessons and finding some general goals in the subject-specific part of the NC that might fit. Thus, she gives an account of how teachers resolve the challenge in a situated, practical manner in their daily lives.

Secondly, the sequence illustrates the focus on curriculum delivery and lesson performance. In school, the lesson plan is a tool for planning the performance of practical work in classrooms. The students have to write the lesson 
plan individually, and based on the plan, they are evaluated on how they perform the lesson.

Finally, the sequence illustrates a tension in positioning. The student accounts for the notion of goals as being taught at the campus, but the mentor has another understanding of goals [1]. Kris defends what he has done, but also accommodates the mentor's view. His answer [4] indicates that he does not recognize the distinction between the general goals for the curricula of social science and the goals in the core curriculum proposed by the mentor. However, he defends what he has done, but chooses to be accountable to the school when engaging in this setting [2]. The mentor assesses the student's "capability" as a teacher at the end of the internship and students are not assessed on their ability to interpret, but based on their procedural actions (Edwards \& Protheroe, 2004; Ottesen, 2007). This aspect frames the mentor conversation and makes it easy to understand why a student would choose to adjust to what is warranted during the activity.

\section{Seminar in pedagogy: "Namedropping is ridiculous"}

This extract is taken from the last seminar in pedagogy, where the focus is on preparation for the upcoming oral exam. A recurring theme during the talk is the participants' use of scientific language. One student, Fiona, argues that one may be a good teacher, even if one does not "know all the concepts." Just before the conversation below took place, the university teacher asked the students what they see as an alternative to scientific language. While Fiona agrees that everyday talk is not necessarily an alternative, she argues that the concepts used in teacher education are often given different meanings. Alex proposes an alternative.

\section{Extract 3}

1. Alex: Instead of asking "what do you mean by Vygotsky's zone of proximal development," I would explain what is meant by the concept and ask, what do you mean by that difference, the development, etc. That is the alternative. Instead of talking about his view, talk about what that view is, how you look at it. Maybe.

2. Geir: Isn't the point that you do not know Vygotsky like that, but that you can use, or compare with what you are doing when teaching? Or what it has to say about learning and teaching? I can reel off everything about Vygotsky, but (...)

3. Teacher: That is pretty irrelevant. Just to reel off and do namedropping, that is ridiculous. One is supposed to use it to reflect about practice, and get a conscious relation to it, that is the point. Otherwise it makes no sense, so I totally agree with you.

What is important in this interaction is that the students and the teacher focus on a shared problem, negotiating what counts as knowledge in an exam situation. 
During the interaction, the students challenge the teacher. In his utterance [1], Alex proposes an alternative to Fiona and the teacher, based on his personal view: "I would..." He suggests how external examiners should pose their question during the examination. Through his account, Alex opens a space for negotiation. Geir supports Alex's suggestion by saying that concepts should be used to reflect on learning and teaching. However, instead of grounding his argument in his personal view, he orients to institutional regulations and what teachers have said in the seminars. The teacher takes up their arguments, and characterizes namedropping as "ridiculous" [3]. In this way, he acknowledges the students' positions as legitimate.

During their talk, they negotiated how to use scientific concepts in relation to practical experiences as teachers. Thus, what counts as knowledge in the forthcoming oral exam is to use scientific concepts to reflect on practical issues.

\section{Oral exam: "Do you know what $I$ have in mind?"}

In this extract, we follow Kris' oral examination in pedagogy and history. The examination is undertaken by a teacher in pedagogy (TP) and a teacher in subject didactics (TSD). The students were told to prepare a presentation using an example from their internship. Kris chose to show a few minutes from a movie ("Saving Private Ryan"). His presentation was about a lesson he had planned. Building on a dialogical perspective (Bakhtin and Vygotsky), he explains how to use experiences (through watching and talking about a movie) to develop pupils' concepts and oral skills. After the presentation, a more traditional examination takes place, where the two teachers examine according to their own specialties. The TP is concerned about the teacher's role both as a subject expert and as a person with responsibility for the care and wellbeing of pupils, and asks Kris to elaborate on this. Kris talks about teacher professionalism, and the teacher follows up:

\section{Extract 4}

1. TP: Teacher professionalism, I want to bring that a bit further because it consists of some components, do you know which components I have in mind?

2. Kris: Hmm, no, I'm thinking of, professionalism is about...

3. TP: Let me give you a clue so we don't spend time on this. Bergem classifies this, (...) and he puts up three categories for competence.

4. Kris: $\operatorname{Ehmm~(...)~}$

5. TP: Do you know what I have in mind?

6. Kris: I have to admit I (...)

7. TP: [But you (...)

8. Kris: I'm following you, it is something about, if you categorize something. If you give me the categories I will see if I, I'm thinking of knowledge production, you need to impart knowledge, he uses another term, ehm (...) 
9. TP: [Subject competence, pedagogical competence, and competence of professional ethics.

10. Kris: Okay, then I'm with you. (...) A bit related to this are the three components of the development of practice theory [Kris goes on to explain the model of the practical triangle].

In the interaction, the student answers questions from the TP. Kris has just talked about teacher professionalism and the TP wants him to mention three specific elements in relation to this [1]. Teacher professionalism is covered in different parts of the curriculum, and it is difficult for Kris to know what the teacher has in mind. He tries to give an account, but is interrupted by the TP, who explains that he wants him to use Bergem's classification of competence [3]. Kris is not able to reproduce these categories, but tries to provide an account without remembering the exact terms [8]. Again the teacher interrupts, this time giving him the right answer. The "naming" of the categories supplies Kris with information that enables him to continue, and give an account for how he sees this classification in relation to another concept in the curriculum.

After the examination, the two teachers have a short meeting to discuss the student's oral presentation and decide on a set of marks for each of the two subjects. Based on the student's written portfolio, they have determined the limits for adjusting his marks up or down. It is set a mark for each subject. In the following extract, they discuss the mark for pedagogy.

\section{Extract 5}

1. TSD: But in between the limits that we have, I feel that he pushes the borders quite a bit up.

2. TP: yes? (...)

3. TSD: Well, but I have (...)

4. TP: I'm not sure.

5. TSD: But you had this with the concept of competence that he was not sure of and (...)

6. TP: [But he is quite good on learning theories, and that is an important basis $(\ldots)$

7. TP He could have done it better, I gave him the possibility to improve his grade, but he does not live up to that; when he didn't manage the concept of competence, he doesn't live up to that.

The TSD seems to think that the student gave a better impression in the oral exam than in the portfolio [1], but the TP seems to disagree [2, 4]. However, the TP acknowledges that the student displayed a good understanding of learning theories [6]. The TP seems quite uncertain about deciding on a mark. He explains that he could have improved his grade, but since he did not know the required concepts about competence he does not "live up to that" [7]. When assessing the student, the focus is therefore on what the student does not know. 
In the two sequences from the oral exam, the teachers and the student follow a traditional exam script. Historically, examinations are based on asymmetric relationships: students are expected to come up with "right" answers in accordance to the curriculum, and the university teachers assess the quality of their responses. In his opening presentation, the student accounts for a way of using theory that was negotiated in the seminar (as we saw in Extract 3); he uses a dialogical perspective to account for the development of pupils' concepts. The presentation is seen as good, but in the following examination, the methods of reasoning that are considered legitimate in the seminar no longer count.

\section{Discussion and concluding remarks}

In order to understand the complexity of how student teachers learn to teach, the focus of this article has been to investigate how participants derive meanings from concepts within and between activity systems. In the reform program, several tools were implemented to create a coherent teacher education program. These tools, such as portfolio assessment, and case assignments involved changes in institutional norms and division of labor between students and teachers and, in this way, created conditions for more coherent trajectories for the students (Jahreie \& Ludvigsen, 2007; Rasmussen \& Ludvigsen, 2009). However, these structural conditions do not in and of themselves ensure that participants are deriving meaning from concepts and ideas in a manner intended by the project. An interest this article has been how the meaning of concepts is constructed in different learning spheres, and what characterizes students' positions.

Students need to learn to utilize several theoretically grounded tools, ranging from knowledge of curriculum materials and assessment strategies to techniques for organizing group work and planning students inquiries (Darling-Hammond, 2010). University course work is, however, often too abstract and general (Bråten, et al., 2003; Eriksen, 2004). Scientific concepts are often highlighted in relation to practical experiences, but the relevance between theory and the task at hand is rarely made explicit for the students (Fosse, 2010; Jahreie, 2010b). In other words, the students are left bereft of specific tools to use in classrooms (Darling-Hammond, 2010). Studies of talks between students and university teachers have revealed a few instances where the use of scientific concepts is a shared object for discussion (Fosse, 2010; Jahreie, 2010b). In the analysis, we saw that the students and the teacher focus on a shared problem: negotiating what counts as knowledge in an exam situation. In the talk, they make their ideas and understanding public, as with Alex's account about the use of scientific language. Through his account, he opens a space for negotiation. He can position himself as a "virtual" censor, and it is legitimate for him to formulate his account from that perspective. However, as these are atypical 
forms of interactions, there are no scripts directing the activity. The teachers and students do not have any interactional experience to mediate participation and, thus, to mediate a different understanding of teaching and learning.

This is evident if we look at the oral examination. Even though the structure of the oral examination was changed to a more student-centered approach, such as the one used for seminars, it still represents a scripted site with long historical traditions (Engeström, 2008). In the analysis of the oral examination, we saw that what counts as knowledge are the "right" answers, with the teacher asking questions and the students answering them. There is only one position available, namely that of a student. Kris' accounts are produced from that position; his agency is restricted. It is therefore not surprising that this historical script is foregrounding the intentions of the reform. Both the student and the teacher produce appropriate accounts of what is expected in an exam situation, thus reproducing the traditional exam script. Within the DTE, objects often seem to arise from negotiations saturated with opposition and clashes of interest (Jahreie \& Ludvigsen, 2007).

As we have seen be the case in talks between students and university teachers, instances of interaction between scientific concepts and practical issues are rare in mentoring conversations as well. As illustrated in the empirical analysis, the talk is highly situated. The literature on internships demonstrates robust findings that talks between mentors and students are first and foremost about methods that work, wherein the student teachers are presented with the way teachers think and act on an everyday basis (Edwards \& Protheroe, 2003; Ottesen, 2006; Sundli, 2001).

A promising finding is that in students' collaboration in small groups, warranted ways of understanding teaching and learning are reflected upon and discussed. In the analysis of the students' work with the cases, we saw that the students not only used scientific concepts in negotiating the task, but also explored and negotiated the meaning of scientific concepts. In other words, in their interaction, the tool temporarily became the object (Engeström, 1990). I argue that this shift is crucial for elaborating and refining one's arguments. New interpretations of the scientific concepts give the students the resources to expand their understanding of the task. The analysis of the whole trajectory showed that the tools used to expand and explore the case were expanded from a merely superficial use of scientific concepts to a quite complex theoretical discussion related to the students' practical experiences (Jahreie, 2010b). When the students are given time to collaborate, they are able to reconstruct the object combining the conflicting accounts from the DTE and the school. Other studies underpin the importance of engaging with other learners to gain new insights into the phenomena the students are tackling (Edwards \& D'Arcy, 2004; Engle \& Conant, 2002).

An overall finding is that crossing the boundaries between the DTEs and the schools is a complex challenge since the historically developed boundaries 
between the two activity systems appear to be rigid and isolated. Even though participants are positioned as, e.g., students, mentors or university teachers, based on the salient rules and division of labor of the activity system, actors also have the option to challenge or expand their positions. However, the legitimacy of their accounts varies between learning spheres, leading to disturbances and making evident the inherent contradictions in the activity system. This leads to a tension in positioning, which is a recurrent dilemma students face during their learning trajectory. In teacher-led activities at the DTEs and the schools, the participants rarely negotiate conflicting perspectives of knowledge and concepts. In the process of making sense of scientific concepts, the students struggle to open up spaces for a conceptual elaboration, but the teachers and mentors defend the boundaries of "their" activity and do not accept the students' accounts as valid from their positions as, respectively, a student and a teacher (Ottesen, 2006). This can be explained by the different motives that drive the two activity systems. School activities are motivated by the performance of teaching, whereas activities at DTEs are motivated by learning, thus the legitimate position is that of a student. However, this article has shown instances in the interactions when it is legitimate for the students to position themselves as authorities, censors, teachers, or learners. In group work, the student teachers coconstruct meanings and change the object in question with the integrated use of different tools. They act in a space where they are in a position to experiment with different forms for doing, thus positioning themselves as learners, which may erase or combine current boundaries in teacher education.

This article has shown that during the learning trajectories, the students encounter divergent discourses and concept understandings. This places heavy demands on the students since they face a variety of expectations in the different settings. From the perspective of the student, it seems reasonable to argue that the contradictions within and between the activity systems serve as constraints on learning. When encountering conflicting expectations without any help from teachers and mentors with the translation work, the student teachers come in an "in-between" position where they struggle to be accountable to both systems. The study also shows instances where students use theoretically grounded tools to reflect on and analyze their practice as teachers. However, to create coherent trajectories for the students, concepts and ideas about teaching and learning must be shared by DTEs and partner schools (Grossman, et al., 2008).

\section{Acknowledgements}

This article is a work with multiple voices. The voice of Associate Professor Eli Ottesen is of tremendous importance, as three of the extracts are taken from studies she has co-authored. Professor Sten Ludvigsen has provided invaluable comments on my thesis, which this article is inspired from. I owe thanks to the student teachers, mentors, and university teachers. Without their help, my research would not be possible. Thanks to the anonymous reviewers for good comments. 


\section{References}

Bråten, I., Strømsø, H. I., \& Olaussen, B. S. (2003). Self-regulated learning and the use of information and communication technology in Norwegian Teacher education. In D. McInerney \& S. Van Etten (Eds.), Research on sociocultural influences on motivation and learning: (Vol. 3, pp. 199-221). Greenwich, CT.: Information Age Publishing.

Burn, K. (2007). Professional knowledge and identity in contested discipline: challenges for student teachers and teacher educators. Oxford Review of Education, 33(4), 445-467.

Daniels, H. (2007). Discourse and identity in cultural-historical activity theory: A response. International journal of Educational Research, 46, 94-99.

Darling-Hammond, L. (2006). Constructing 21st-century teacher education. Journal of Teacher Education, 57, 300-314.

Darling-Hammond, L. (2010). Teacher education and the American future. Journal of Teacher Education, 61(1-2), 35-47.

Darling-Hammond, L., \& Bransford, J. (2005). Preparing teachers for a changing world What teachers should learn and be able to do. San Francisco: Jossey-Bass.

Edwards, A., \& D'Arcy, C. (2004). Relational agency and disposition in sociocultural accounts of learning to teach. Educational Review, 56(2), 147-155.

Edwards, A., \& Protheroe, L. (2003). Learning to see in classrooms: What are student teachers learning about teaching and learning while learning to teach in schools? British Educational Research Journal, 29(2), 227-242.

Edwards, A., \& Protheroe, L. (2004). Teaching by proxy: Understanding how mentors are positioned in partnerships. Oxford Review of Education, 30(2), 183-197.

Eisenhart, M. (2009). Generalization from qualitative inquiry (pp. 51-67). New York, Milton Park: Routledge.

Ellis, V. (2008). Exploring the contradictions in learning to teach: The potential of developmental work research. Changing English An International Journal of English Teaching, 15(1), 53-63.

Engeström, Y. (1990). When is a tool? Multiple meanings of Artifacts in Human Activity. Helsinki: Orienta-Konsultit Oy.

Engeström, Y. (2008). From teams to knots: Activity-theoretical studies of collaboration and learning at work Cambridge: Cambridge University Press.

Engeström, Y., Puonti, A., \& Seppänen, L. (2003). Spatial and temporal expansion of the object as a challenge for reorganizing work. In D. Nicolini, S. Gherardi \& D. Yanow (Eds.), Knowing in organizations: A practice-based approach. Armonk: Sharpe.

Engle, R. A., \& Conant, F. R. (2002). Guiding principles for fostering productive disciplinary engagement: Explaining an emergent argument in community of learners classroom. Cognition and Instruction, 20(4), 399-483.

Eriksen, O. (2004). IKT som endringsfaktor i lererutdanningen: rapporten fra PLUTOprosjektet (2000-2003) ved Høgskolen i Østfold: Avdeling for Lærerutdanning. Høgskolen i Østfold.

Fosse, B. O. (2010). Lærerstudenters innramming og forståelse av tiplasset opplæring. En studie av kollektive laringsprosesser i ulike kontekster ved en praktisk-pedagogisk utdanning. University of Oslo, Oslo.

Furlong, J., \& Maynard, T. (1995). Mentoring student teachers The growth of professional knowledge London, New York: Routledge.

Furlong, J., McNamara, O., Campbell, A., Howson, J., \& Lewis, S. (2008). Partnership, policy and politics: initial teacher education in England under New Labour. Teachers and Teaching, 14(4), 307-318. 
Grossman, P., Hammerness, K. M., McDonald, M., \& Ronfeldt, M. (2008). Constructing coherence: Structural predictors of perseptions of coherence in NYC teacher education programs. Journal of Teacher Education, 59(4), 273-287.

Guyton, E., \& McIntyre, D. (1990). Student teaching and school experiences. In W. R. Houston (Ed.), Handbook of research on teacher education (pp. 514-535). New York: Macmillian.

Holland, D., Lachicotte, W., Skinner, D., \& Cain, D. (1998). Identity and agency in cultural worlds. Cambridge, MA.: Harvard University Press.

Jahreie, C. F. (2010a). Learning to teach. An activity-theoretical study of student teachers' participation trajectories across boundaries. University of Oslo, Oslo.

Jahreie, C. F. (2010b). Making sense of cultural tools in case work: Student teachers' participation trajectory. Teaching and Teacher Education, 26(6), 1229-1237.

Jahreie, C. F., \& Ludvigsen, S. (2003). Transformation of co-developing activity systems interventions, boundaries and boundary zone activities. Paper presented at the 2003 EARLI Conference, Padova, Italy.

Jahreie, C. F., \& Ludvigsen, S. R. (2007). Portfolios as boundary object: Learning and change in teacher education. Research and Practice in Technology Enhanced Learning. 2(3), 299-318.

Jahreie, C. F., \& Ottesen, E. (2010a). Constructions of boundaries in teacher education: Analyzing student teachers' accounts. Mind, Culture, and Activity, 17(3), 212-234.

Jahreie, C. F., \& Ottesen, E. (2010b). Learning to become a teacher: Participation across spheres for learning. In V. Ellis, A. Edwards \& P. Smagorinsky (Eds.), Cultural-historical perspectives on teacher education and development. Learning teaching (pp. 131-146). London: Routledge.

Kerosuo, H. (2006). Boundaries in action: An activity-theoretical study of development, learning and change in health care for patients with multiple and chronic illnesses. Doctoral dissertation thesis, University of Helsinki, Helsinki.

Lambert, P. (2003). Promoting developmental transfer in vocational teacher education. In T. Tuomi-Gröhn \& Y. Engeström (Eds.), Between education and work: New perspectives on transfer and boundary crossing (pp. 233-257). Amsterdam: Pergamon Press.

Ministry of Education and Research (2009). White paper no 11, 2008/2009. 'Lcereren, rollen og utdanningen' ['The teachers, their role, and the education']. Oslo, Norway: Ministry of Education and Research.

Ottesen, E. (2006). Talk in practice: Analysing student teachers' and mentors' discourse in internship. Doctoral dissertation thesis, University of Oslo, Oslo, Norway.

Ottesen, E. (2007). Teachers "in the making": Building accounts of teaching. Teaching and Teacher Education, 23(5), 612-623.

Rasmussen, I., \& Ludvigsen, S. (2009). The hedgehog and the fox: A discussion of the approaches to the analysis of ICT reforms in teacher education of Larry Cuban and Yrjö Engeström Mind, Culture, and Activity, 16(1), 83-104.

Sundli, L. (2001). Veiledning i lcererutdanningens praksis-mellom refleksjon og kontroll [Counselling in the practicum in teacher education-between reflection and control]. Oslo: Høgskolen i Oslo.

Wertsch, J. (1991). Voices of the mind. A sociocultural approach to mediated action. Cambridge, MA: Harvard University Press.

\footnotetext{
${ }^{1}$ See the articles (Jahreie, 2010b; Jahreie \& Ottesen, 2010a, 2010b) for an in-depth explanation for how the extracts were selected and the analyses performed in each case.
} 
2 The practical triangle refers to a well-known Norwegian pedagogical concept. It is a threelevel triangle, where the first level refers to teachers' teaching, the second one to teachers' reflections on their own teaching and the third on researchers' reflections about teaching. ${ }^{3}$ Vygotsky's ZPD and the notion of the practical triangle originate from two different learning theories, but both concepts are visualized in a triangle. 